\title{
Exploring barriers and facilitators for mental health professionals delivering behavioural activation to young people with depression: qualitative study using the Theoretical Domains Framework
}

Kate Whittenbury, Leopold Kroll, Bernadka Dubicka and Eleanor R. Bull

\section{Background}

Depression prevalence among young people is increasing, with growing pressures on specialist mental health services. Manualised behavioural activation therapy may be effective for young people, and can be delivered by a range of mental health professionals (MHPS). This study explored clinician perspectives of barriers and facilitators to implementing behavioural activation with young people in routine practice.

\section{Aims \\ We conducted a qualitative study with individual semi-structured interviews with MHPS, as part of a wider feasibility study.}

\section{Method}

Participants were mental health professionals (therapists and supervisors) from two UK NHS sites delivering manualised behavioural activation for young people. Data were analysed with an inductive followed by deductive approach, applying the Theoretical Domains Framework (TDF) to understand key influences on practice change. Identified domains were mapped onto possible behaviour change techniques (BCTs) to support implementation, using the Theory and Techniques Tool (TTT).

\section{Results}

Nine MHPS were interviewed. Thirteen of fourteen TDF domains were relevant, including perceived professional identity, beliefs about own capabilities and perceived positive or negative consequences of using manualised behavioural activation, social influences, memory and attention, and environmental resources. Fourteen theory-linked BCTs were identified as possible strategies to help clinicians overcome barriers (e.g. integrating behavioural practice/rehearsal, prompts and persuasive communications within training, and supervision).

\section{Conclusions}

Behavioural science approaches (TDF, TTT) helped conceptualise key barriers and facilitators for MHPs delivering manualised behavioural activation with young people. Interventions using BCTs to address identified barriers could help the implementation of new therapies into routine practice, working to bridge the research-practice gap in clinical psychology.

\section{Keywords}

Behavioural activation; children and young people; theoretical domains framework; implementation; depression.

\section{Copyright and usage}

(c) The Author(s), 2022. Published by Cambridge University Press on behalf of the Royal College of Psychiatrists. This is an Open Access article, distributed under the terms of the creative Commons Attribution licence (https://creativecommons.org/ licenses/by/4.0/), which permits unrestricted re-use, distribution, and reproduction in any medium, provided the original work is properly cited.
Prevalence rates of depression among young people are rising worldwide. ${ }^{1}$ Services remain under-resourced and understaffed, with experts arguing that we are experiencing a children's mental health crisis. ${ }^{2}$ Currently, in the UK, National Institute for Health and Care Excellence clinical guidelines ${ }^{3}$ for young people with moderate-to-severe depression recommend 12 weeks of cognitive-behavioural therapy (CBT) within a specialist Child and Adolescent Mental Health Service (CAMHS), typically including both cognitive and behavioural treatment approaches aiming to help young people think and act differently to break negative thinking and behaviour patterns thought to maintain depression. Behavioural activation is a more behaviourally oriented psychological treatment focusing on helping a person do more activities that are valued (inherently rewarding) in a structured and achievable way, to improve mood. Behavioural activation has an established evidence base as an alternative to CBT in studies with adults, ${ }^{4}$ and is proving promising for young people. ${ }^{5}$ Importantly, manualised behavioural activation can be delivered by mental health professionals (MHPs) without in-depth specialist training, and so may be less costly than traditional CBT. ${ }^{6}$ Although available in some CAMHS, in the UK as in other countries, behavioural activation is not being implemented consistently or in a structured way. ${ }^{7}$ It is important to study implementation factors, such as professionals' perceptions of delivering behavioural activation particularly in the current global mental health context. ${ }^{8}$ To implement new therapies and evidence into routine practice, MHPs often need to make substantial changes to their practice behaviours at work. ${ }^{9}$ However, the research-practice gap in healthcare (including mental healthcare) is well known. ${ }^{10}$ It is estimated that $30-40 \%$ of patients do not receive evidence-based practice, with as much as $25 \%$ of healthcare given being needless or even damaging. ${ }^{11}$ Applying behavioural science to identify barriers and facilitators can provide clear explanations of mechanisms of change, and can assist researchers in understanding why health professionals do or do not change their behaviour and, consequently, why interventions are or are not implemented effectively. ${ }^{12}$ Several tools have been recently developed by groups of psychological researchers aiming to help others understand and facilitate implementation of new therapies and evidence in practice. One of these tools is the Theoretical Domains Framework (TDF), a synthesis of 33 behavioural theories of behaviour change forming 14 domains that create a framework that researchers can use as a theoretical basis to understand cognitive, social, emotional and environmental influences on healthcare professionals' behaviour. ${ }^{13}$ The TDF has been used extensively in implementation research investigating facilitators and barriers of implementing interventions within various healthcare settings. ${ }^{9,14}$ National Institute for Health and Care Excellence guidelines suggest research should investigate which 
behaviour change techniques (BCTs) are most likely to stimulate and support behaviour change, resulting in successful implementation of new interventions into routine practice. ${ }^{15}$ However, this process has not been widely used in clinical psychology, and has never been used to explore MHP implementation of behavioural activation for young people. Another is a taxonomy of 93 BCTs, defined as active components of an intervention designed to change a behaviour. ${ }^{16}$ BCTs can be used as practical, theorylinked strategies to address identified barriers to behaviour change in a defined context, leading to better implementation practices and thus patient outcomes. ${ }^{17}$ The most recent behavioural science development, the Theory and Techniques Tool (TTT), ${ }^{18}$ was developed to assist with this linkage process.

This study applied the TDF and TTT to explore MHPs' perceived barriers and facilitators of delivering manualised behavioural activation in two National Health Service (NHS) sites, as part of a wider feasibility study. This study aimed to understand implementation barriers and facilitators perceived by MHPs implementing manualised behavioural activation with young people in CAMHS settings, using the TDF; and map relevant TDF domains to BCTs by using the TTT to determine relevant intervention components that could support MHPs' implementation of manualised behavioural activation in future.

\section{Method}

The Consolidated Criteria for Reporting Qualitative Research (COREQ) was used to guide this qualitative investigation. ${ }^{19}$ This study explored perspectives of MHPs delivering behavioural activation as part of a mixed-methods feasibility study. The wider feasibility study details, fidelity measures and participant outcomes are reported in full elsewhere. ${ }^{20,21}$

In brief, seven MHPs delivered eight sessions of manualised behavioural activation to 33 young people aged 12-17 years, over 10 months (July 2019 to April 2020), in two specialist NHS CAMHS sites within the North-West of England. CAMHS are the UK NHS mental health services for children and young people, delivering evidence-based psychological therapies to help ameliorate affective or behavioural problems. The eight behavioural activation workbooks and programme overall (training, implementation, delivery) were co-produced with young people and clinicians, with the first four focusing on orientation of the behavioural activation model, values and goals, and activity scheduling; and the remainder focusing on the role of avoidance, overcoming barriers, future planning and depression relapse prevention. MHPs were offered a training day followed by half a day of training and MHP discussion days every 3 months, alongside regular clinical supervision.

For this study, using a homogeneous purposive sampling technique, all MHPs participating in the wider study were invited by letter to take part in a semi-structured interview surrounding their experience during the active study timeframe. An openended question topic guide was developed ${ }^{22}$ to explore in-depth perspectives of barriers and facilitators to implementing behavioural activation with young people (see Supplementary File 1 available at https://doi.org/10.1192/bjo.2022.7). The researcher was independent from the wider feasibility study team, had previous experience of conducting qualitative research and interviews and was trained in research methods to a Master's degree level. The interviewer established relationships with the participants implementing the new behavioural activation intervention before data collection began, and kept a reflexive journal throughout the research project. Written informed consent was obtained from all participants. Interviews were audio-recorded with a passwordprotected mobile phone, with the participant's consent. Audio recordings taken within interviews were transcribed onto an encrypted computer within 4 days of the original interview, and the recording was deleted. All identifiable information was anonymised in transcripts to secure participants' privacy. The authors assert that all procedures contributing to this work comply with the ethical standards of the relevant national and institutional committees on human experimentation and with the Helsinki Declaration of 1975, as revised in 2008. All procedures involving human patients were approved by the Health Research Authority's Integrated Research Application System (project 257613).

\section{Data analysis}

An experimental approach to thematic analysis was used to analyse the interview transcripts. The TDF was used as a structure to analyse and interpret data. ${ }^{23}$ Two coders independently followed ${ }^{24}$ Six phases of thematic analysis ${ }^{25}$ alongside those within a guide to using the TDF for implementation studies. ${ }^{26}$ Familiarisation with the data-set began through transcription and by re-reading transcripts. Then, each transcript was inductively coded and code names were generated to identify points of interest in the data relevant to the research question. ${ }^{24}$ Code names were then matched to domains of the TDF, following previous implementation studies using the TDF (e.g. Alexander et $\mathrm{al}^{27}$ ).

Additionally, to identify BCTs to support implementation, key domains were mapped onto BCTs by the novel TTT. ${ }^{18}$ This visually represents the strength of evidence for 74 BCTs to help improve each TDF domain (labelled mechanisms of action in the TTT). The strength of these links (between BCTs and mechanisms of action) was established by a literature review of 277 behaviour change studies ${ }^{28}$ and an expert study of consensus. ${ }^{29}$ In the present study, 39 BCTs were identified and then checked with the APEASE (affordability, practicality, effectiveness, acceptability, side-effects, equity) criteria, ${ }^{30}$ a tool used to access the feasibility of BCTs and interventions in real-life contexts. ${ }^{31}$ Research studies usually concentrate on the effectiveness of interventions. The APEASE criteria are used to assess if such interventions are feasible in real clinical practice situations, and can be used to modify, prioritise or omit parts of the intervention. ${ }^{30}$

The lead study author evaluated each potential BCT against each APEASE criterion, with strong reference to the practical suggestions gathered from clinicians in the interviews, and checked them with the study leads, a team of experienced academic-practitioner psychologists and psychiatrists.

\section{Results}

\section{Interviews and participant characteristics}

Nine face-to-face interviews were conducted, lasting 20-50 mins at each participant's place of work. All participants were NHS MHPs. Seven participants were 'implementation staff (i.e. MHPs delivering the therapy), including three assistant psychologists and four psychological well-being practitioners. The two other participants were supervisors of the implementation staff: a CBT therapist and a clinical psychologist. Participants were based at one of two NHS CAMHS in the North of England (termed site A and site B for anonymity). Participants were aged between 21 and 45 years, eight out of nine were female, and all participants had English as their first language. Implementation staff varied in experience levels with behavioural activation similarly to variation seen in real-life CAMHS teams. Two professionals at two different sites had used a different behavioural activation manual before. The five other professionals had no prior experience of behavioural activation delivery. 
Full details of patients included are published in the outcome paper. ${ }^{20}$ In brief, 33 young people aged $12-17$ years were involved; 11 were male $(33 \%)$ and 22 were female $(67 \%)$; and patients were of mixed (White and Asian) $(n=2)$, Asian $(n=2)$, Black (African) $(n=1)$ or White British $(n=28)$ ethnicity.

\section{Barriers and facilitators to implementation}

Interviews captured a diverse range of perceived barriers and facilitators to implementation of behavioural activation with young people. Initial codes mapped onto 13 out of 14 TDF domains identified as relevant, including beliefs about capabilities; professional identity and role; social influences; beliefs about consequences; memory, attention and decision-making; environmental resources and context; intentions; knowledge; skills; reinforcement; optimism and emotions (see Table 1). As explored below, domains interacted with one another (see Fig. 1). Beliefs about capabilities and professional roles/identity were dominant domains in the data and often interlinked, suggesting that how an MHP viewed themselves and their capabilities was interconnected, and influenced the likelihood of a clinician using the new intervention. Another central domain identified throughout the interviews was beliefs about consequences. Intervention facilitators' use of the new programme was influenced by their perceptions of how effective the intervention would be and whether the manualised therapy was 'enough' as a standalone intervention for a particular young person. Also, social influences were found to influence the uptake and implementation of the new intervention by MHPs. The perceived social influences differed between the two NHS centres, which affected the implementation of the behavioural activation intervention differently. Overall, participants perceived the new intervention positively, but implementation was subject to a number of influences. Key domains of interest are summarised below.

\section{Beliefs about capabilities and professional role/identity}

The beliefs about capabilities domain is defined as 'the acceptance of the truth or reality of an individual's capabilities or talents which can be put to beneficial use'. ${ }^{13}$ The professional identity and role domain is described as a person's consistent set of behaviours and displayed personal qualities in a work setting. There was a consistent pattern within the data-set of beliefs about capabilities and professional role/identity themes interrelating and acting as either facilitators or barriers to the behaviours involved in implementing the new intervention. For example, MHPs who perceived themselves as new clinicians initially had low confidence in their capabilities of enacting behavioural activation as specified in the manual. However, they perceived practicing using the manual as a way of increasing their capability; therefore, perceiving oneself as a new clinician ultimately facilitated the use of the new intervention.

'I am a relatively new clinician, I feel at the moment I'm pretty low in confidence, erm, [ ... ] I think the next patient I have, as I have more practice, I'll know how to make things a little different or words things differently so it sounds better or erm, just kind of comes across better and maybe I will understand it more. [ ... ].' (Clinician 101, site A)

On the other hand, MHPs who perceived themselves as specialised or experienced clinicians appeared less open to behavioural activation as a new and unfamiliar way of working, feeling more capable with their usual methods. One participant suggested that the introduction of a new intervention may call into question their current methods of practice, and acted as a barrier.

'[ ... ] so when you are less experienced you will go in and just hoover up every skill [ ... ] but for specialists like me you are like "I use this, I know this works for me" [ ... "what if I'm not particularly good at this?" I think it is harder to [ ... ] accept it.' (Clinician 103, site A)

\section{Social influences}

The TDF describes social influences as the interpersonal processes that can change the way a person thinks, feels and behaves. Social influences were found to be a facilitator in implementing the new behavioural activation intervention; for example, MHPs felt supported within group supervision and training. Coming together as a group made MHPs feel calm about communicating their concerns, and helped individuals overcome challenges when using the intervention, by learning from others.

'I quite liked group supervision [ ... ] you kind of share experiences, and like we are new clinicians and [supervisors] are more experienced $[\ldots]$ so it is nice to share our experiences. [... ] sometimes in 1-1 supervision you feel like as a new clinician especially you can't sort of say everything [ ... ].' (Clinician 102, site A)

'I think it was useful to come together and speak to people that had already started using it and what challenges they had faced. [...] another clinician may have a top tip that has worked really well.' (Clinician 106, site B)

Additionally, MHPs noted that there were differences in perceived social support within sites and this may have influenced the uptake of the new intervention.

' $[. .$.$] there are different personalities. I know site B have a dif-$ ferent spread of practitioners who are using this compared to ours, they seem to have gone more with [...] people with more experience rather than we have given it to assistant psychologists who naturally I think, because their interest is getting on to a clinical psychology doctorate, are quite happy to do a clinical intervention [...] and they are quite open and have that mind set. Maybe, for other professionals with different backgrounds it's not a priority.' (Clinician 103, site A)

One aspect of this could have been the main therapeutic traditions used in the organisations, with site A tending to be used to more integrative therapeutic approaches, so perhaps MHPs felt adopting new ways of working would be supported by peers. ${ }^{32}$

\section{Beliefs about consequences}

The beliefs about consequences domain refers to how an individual perceives the possible results of performing a certain behaviour, including the characteristics of the outcome and anticipated regret and consequences. ${ }^{13}$ In this study, MHPs perceived the beliefs about consequences domain acted as both a barrier and facilitator to implementing the new behavioural activation intervention. Some MHPs perceived behavioural activation as 'not being enough' as a single intervention, thinking that the young people they were working with would require further input after any behavioural activation intervention. They suggested that in some cases, they decided to refer patients directly to a specialised MHP for an alternative treatment, such as CBT or cognitive analytic therapy, rather than a less experienced MHP who would implement the behavioural activation intervention. Therefore, some beliefs about consequences acted as barriers to implementation of the novel behavioural activation manual.

'Yes, so that is a barrier I would say. I think because even though we say, "yes, we accept comorbidity", there is always a feeling that it may need more or it needs a case manager that can manage it and do the work, [...] And if the thought is that, yes if they see an assistant (psychologist) for 8 weeks but then it's going to need more work, then they 
Table 1 Allocation of codes onto domains of the Theoretical Domains Framework

\begin{tabular}{|c|c|c|}
\hline TDF domain & $\begin{array}{l}\text { Barrier or } \\
\text { facilitator }\end{array}$ & Codes \\
\hline Knowledge & Facilitator & $\begin{array}{l}\text { Rationale for using } \\
\text { behavioural activation } \\
\text { Previous knowledge } \\
\text { of behavioural activation } \\
\text { Behavioural activation } \\
\text { simplistic model } \\
\text { Previous evidence of } \\
\text { behavioural activation }\end{array}$ \\
\hline Skills & $\begin{array}{l}\text { Facilitator or } \\
\text { barrier }\end{array}$ & $\begin{array}{l}\text { Previous experience of using } \\
\text { behavioural activation } \\
\text { No previous therapeutic } \\
\text { experience } \\
\text { Using the manual flexibly } \\
\text { Gaining new skills } \\
\text { Hung up on techniques }\end{array}$ \\
\hline $\begin{array}{l}\text { Professional role } \\
\text { and identity }\end{array}$ & $\begin{array}{l}\text { Barrier or } \\
\text { facilitator }\end{array}$ & $\begin{array}{l}\text { New professional } \\
\text { Inexperienced professional } \\
\text { Specialised clinician } \\
\text { Shaky professional } \\
\quad \text { confidence } \\
\text { Set in ways } \\
\text { Too specialised }\end{array}$ \\
\hline $\begin{array}{l}\text { Beliefs about } \\
\text { consequences }\end{array}$ & $\begin{array}{l}\text { Barrier or } \\
\text { facilitator }\end{array}$ & $\begin{array}{l}\text { Behavioural activation can be } \\
\text { effective in treating low } \\
\text { mood } \\
\text { Widen access to therapies } \\
\text { Could be used by clinicians } \\
\text { Decrease waiting list } \\
\text { May not be enough for some } \\
\text { clients } \\
\text { May be patronising } \\
\text { Too simplistic } \\
\text { May not work with } \\
\text { comorbidities } \\
\text { Children and young people } \\
\text { need to understand } \\
\text { rationale of behavioural } \\
\text { activation } \\
\text { Age appropriate } \\
\text { Older children and young } \\
\text { people will not like it } \\
\text { Behavioural activation is very } \\
\text { repetitive }\end{array}$ \\
\hline Optimism & Facilitator & $\begin{array}{l}\text { Positive before starting } \\
\text { Excited to try something new } \\
\text { Effectiveness of behavioural } \\
\text { activation } \\
\text { Others like behavioural } \\
\quad \text { activation }\end{array}$ \\
\hline $\begin{array}{l}\text { Beliefs about } \\
\text { capabilities }\end{array}$ & $\begin{array}{l}\text { Barrier or } \\
\text { facilitator }\end{array}$ & $\begin{array}{l}\text { Low in confidence } \\
\text { Practice will make me better } \\
\text { Need to do everything } \\
\quad \text { perfectly } \\
\text { Saying the wrong thing } \\
\text { Things going wrong } \\
\text { In the deep end } \\
\text { High in confidence } \\
\text { Dip in and out } \\
\text { Stuck in ways } \\
\text { Invalidates old ways } \\
\text { Getting stuck }\end{array}$ \\
\hline
\end{tabular}

\section{Example quotes}

'Erm, to be honest I have not had a lot of experience in using behavioural activation so it was quite interesting in the training, I was a bit tentative before, because of not having the prior knowledge.' (Clinician 104)

'I think because I get the whole idea around behavioural activation that's helped me a bit I think if I was coming to it completely fresh, I would be a bit disorientated because of the bubbles and stuff all over the place.' (Clinician 108)

'I've gone through IAPT course, part of my training was using behavioural activation for low mood and depression anyway, which was something that I have been doing for 2 years' (Clinician 103)

'I think it depends on the skill set of the person, they are going to need. If I hadn't used behavioural activation before, I think counselling skills help and I think pastora people using it would need that input because it definitely helps.' (Clinician 105)

'I am a relatively new clinician, so I was quite apprehensive. I've done an undergraduate degree in psychology and you learn the basics of therapy and a bit of CBT, but I'd never actually done it in practice.' (Clinician 102)

'I guess if you are training or just starting out it is really good but if you are wellestablished in your own therapeutic work following someone else's can be quite difficult.' (Clinician 108)

'Yes, so that is a barrier I would say. It's because they are busy and I think because even though we say, "yes, we accept", comorbidity, there is always feeling that it may needs more or it needs a case manager that can manage it and do the work, rather than getting a case manager and then a second person to do the therapeutic work. I mean also the capacity of the new practitioners we have got.' (Clinician 107)

'With staff, I think because the majority of staff here had used behavioural activation before they were already like we are doing this anyway so it might as well go towards the research erm, I think they use a different booklet so there was a feel of let's try something new and I think the clinicians that had been using the other manual for a while were happy for a change and there are a couple of new clinicians like me who were quite nervous but also excited to actually do something with the young people.' (Clinician 102)

'I thought it was a really good idea. It's not the first behavioural activation manual I have heard about because I work some of the time on the IAPT for the children and young person training and I knew about a pre-existing behavioural activation manual which was actually being used in this service, so this was another one being brought it, and I was curious but excited, yeah.' (Clinician 109)

'I felt it was clunky at first because I wasn't familiar with the material but the more you use it, the more you get to know what is coming. Erm, so I think the more I use it I will feel more comfortable and go a bit off grid with is, so you can bring in your own stuff as well and flip things round and be a bit more confident in doing that.' (Clinician 105)

'Erm, because of my training and my particular role, I've gone through IAPT course, part of my training was using behavioural activation for low mood and depression anyway, which was something that I have been doing for 2 years with a slightly altered model.' (Clinician 103) 
Table 1 (Continued)

\begin{tabular}{|c|c|c|c|}
\hline TDF domain & $\begin{array}{l}\text { Barrier or } \\
\text { facilitator }\end{array}$ & Codes & Example quotes \\
\hline Reinforcement & Facilitator & Advancement in career & $\begin{array}{l}\text { 'I think because their interest is getting on to a clinical psychology doctorate, they are } \\
\text { quite happy to a clinical intervention around that and they are quite open and have } \\
\text { that mind set.' (Clinician 103) } \\
\text { 'I think some services you have to be really really well trained to do it but then there } \\
\text { obviously isn't that many clinicians, so I think it's better for sort of new clinicians to } \\
\text { be able to do something because then more people are getting seen.' (Clinician 102) }\end{array}$ \\
\hline Intentions & Barrier & $\begin{array}{l}\text { Intentions changing } \\
\text { Intentions not to use new } \\
\text { intervention }\end{array}$ & $\begin{array}{l}\text { 'I think it was deliberate in terms of there was a bit of concern around risk, and the way I } \\
\text { work is pretty rare where I get them to come in and say "let's go" and go through } \\
\text { session, session, session. Maybe they have been waiting for the right cases and } \\
\text { when you are less confident there is an avoidance and you are more likely to go "oh } \\
\text { I'm quite busy", or "I can't do it because I have this to do", erm, it's something that } \\
\text { I've done. I don't whether there was a delay in referrals, getting cases through.' } \\
\text { (Clinician 103) }\end{array}$ \\
\hline Goals & Facilitator & $\begin{array}{l}\text { Action planning } \\
\text { After treatment }\end{array}$ & $\begin{array}{l}\text { 'I am leaving this service and she is going away for } 3 \text { weeks so I have pulled these } 3 \\
\text { sessions together and brought Mum in as co-therapist because even if I was staying } \\
\text { she would have had a 3-week gap. She probably would have forgotten a lot of it so } \\
\text { hopefully if Mum comes she can remind her and where there is a good relationship } \\
\text { with their parent it can really help.' (Clinician 106) }\end{array}$ \\
\hline $\begin{array}{l}\text { Memory, attention } \\
\text { and decision- } \\
\text { making }\end{array}$ & Barrier & $\begin{array}{l}\text { Training was woolly } \\
\text { Busy professionals can forget } \\
\text { to use it } \\
\text { Lack of awareness } \\
\text { Decided to use established } \\
\text { therapies } \\
\text { Case-load and } \\
\text { responsibilities diverted } \\
\text { attention away from new } \\
\text { intervention }\end{array}$ & $\begin{array}{l}\text { 'I think because we are all doing different roles erm, I think it isn't always at the front of } \\
\text { people's minds and day-to-day working conditions get in the way. It took, it was a bit } \\
\text { slow to start with, to get the forms, the books, the forms, the forms, and I guess you } \\
\text { forget if you aren't practicing something you forget.' (Clinician 108) } \\
\text { 'Other management kind of forget we are doing it. They forget yeah because } \\
\text { sometimes I will go in the assessment meeting, and it won't be necessary, so they } \\
\text { have kind of forgot that it is running. Yes, so that is a barrier I would say. It's because } \\
\text { they are busy.' (Clinician 107) }\end{array}$ \\
\hline $\begin{array}{l}\text { Environmental } \\
\text { context and } \\
\text { resources }\end{array}$ & Barrier & $\begin{array}{l}\text { Working in the community } \\
\text { Working in a clinic } \\
\text { Busy } \\
\text { Time pressure } \\
\text { Limited capacity } \\
\text { Changes in job role } \\
\text { Lack of appropriate staff } \\
\text { Communication } \\
\text { Parents } \\
\text { Children and young persons' } \\
\quad \text { home environment }\end{array}$ & $\begin{array}{l}\text { 'I think because we are all doing different roles, erm, I think it isn't always at the front of } \\
\text { people's minds and day-to-day working conditions get in the way. It took, it was a bit } \\
\text { slow to start with, to get the forms, the books, the forms, the forms, and I guess you } \\
\text { forget if you aren't practicing something you forget.' (Clinician 108) } \\
\text { 'I've done session one with him but then he has been off, he's broken his arm and then } \\
\text { he was excluded from school and then he was late so missed his session and I } \\
\text { found that a little bit and because of the school holidays I've not had a clear run with } \\
\text { him, erm, so obviously there are little barriers like that.' (Clinician 104) }\end{array}$ \\
\hline Social influences & Facilitator & $\begin{array}{l}\text { Learning from others } \\
\text { Experienced or } \\
\text { unexperienced clinicians } \\
\text { Do not feel like the only one } \\
\text { Communication between } \\
\text { staff is helpful } \\
\text { Champions in service } \\
\text { What clients expect from } \\
\text { therapy } \\
\text { Positivity of intervention } \\
\text { spreading from others }\end{array}$ & $\begin{array}{l}\text { 'I think it was useful to come together and speak to people that had already started } \\
\text { using it and what challenges they had faced. So, it was really nice and I think we } \\
\text { need more of them. Just because if I think it's nice and everyone will deliver it } \\
\text { differently and if you have something you are getting stuck on another clinician may } \\
\text { have a top tip that has worked really well, I think it's valuable having that space to } \\
\text { have a chat.' (Clinician 106) } \\
\text { 'I think everyone has been quite positive towards it because everyone, I know there are } \\
\text { other members that have used manualised interventions and behavioural activation } \\
\text { before, they were all quite positive and I think that made me more positive in that I } \\
\text { trust the experience of those people.' (Clinician 104) }\end{array}$ \\
\hline Emotion & Facilitator & $\begin{array}{l}\text { Excited } \\
\text { Nervous } \\
\text { Anxious } \\
\text { Relaxed } \\
\text { Comfortable }\end{array}$ & $\begin{array}{l}\text { 'I was a bit nervous because I have never done any behavioural activation before, erm } \\
\text { so I was a bit nervous about it.' (Clinician 101) } \\
\text { 'Yeah, so, before it I was a little but "ooo" see how it goes, then we got in there and } \\
\text { then it went quite smoothly because it goes through step by step, quite easy, so you } \\
\text { go through each of these sections.' (Clinician 102) }\end{array}$ \\
\hline
\end{tabular}

might as well pass it on to that other specialised person straight away.' (Clinician 107, site A)

Also, some MHPs perceived the seemingly simplistic nature of behavioural activation theory and practice could potentially damage their engagement with the young person they were working with. However, several MHPs did perceive the simplicity and practicality of behavioural activation as a strength for engaging with children and young people who may struggle to access or work with their thoughts and feelings.
'I think whilst the theory of behavioural activation is so simple, [...] until you actually start doing it you won't believe it. I remember when I first got introduced to it, I thought "it is going to be hard to explain this to a child without it being patronising."' (Clinician 106, site B)

' $[\ldots]$ whereas the simplicity may be a weakness $[\ldots]$ it is also a strength. Sometimes kids struggle to understand what they are thinking and feeling and with this, it's really practical [... ].' (Clinician 104, site A) 


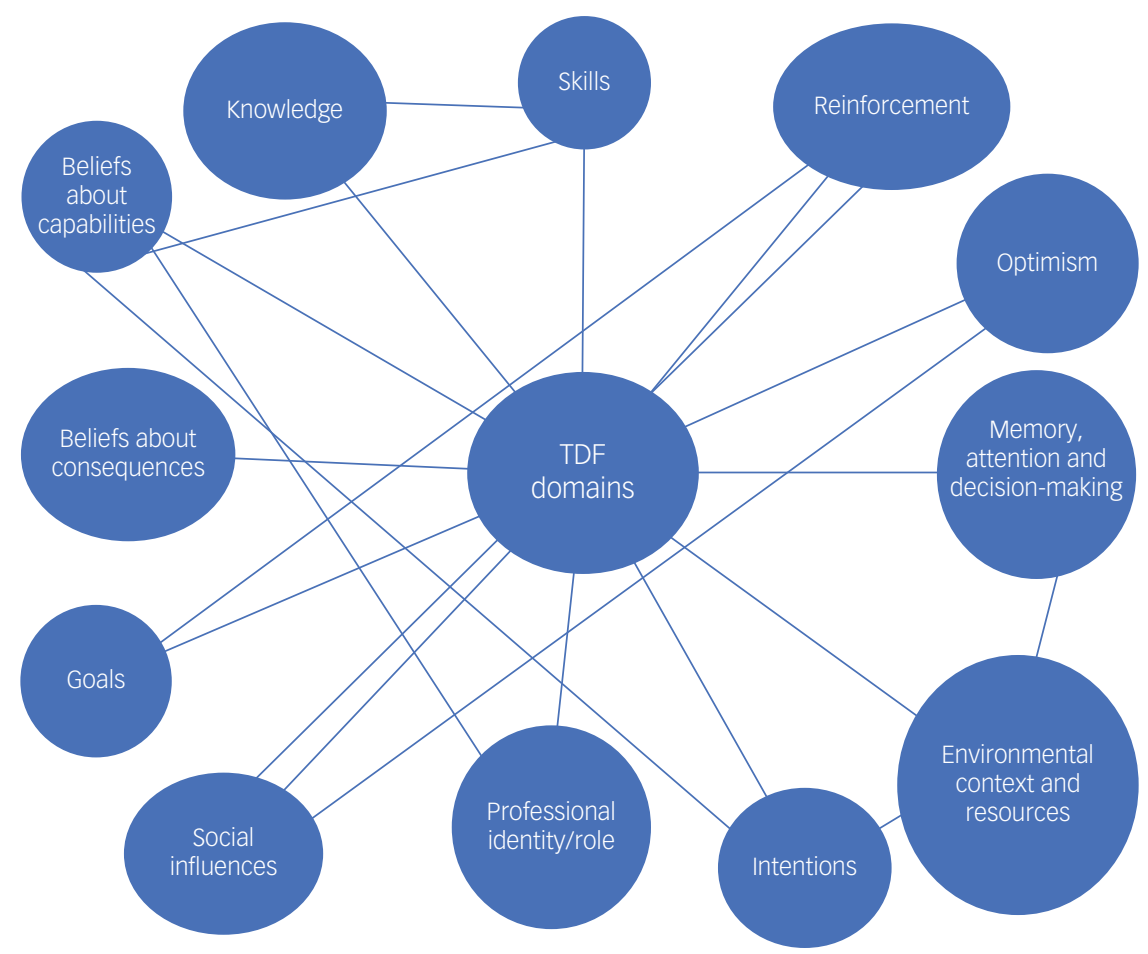

Fig. 1 Thematic map demonstrating interactions between identified TDF domains. TDF, Theoretical Domains Framework.

Further, although a perception from a minority of participants, the supervisors of the implementation staff had positive beliefs about the consequences of introducing the new behavioural activation intervention. The clinical psychologist (a supervisor) interviewed perceived benefits of using the new intervention as it had reduced the CBT waiting list, giving more children and young people access to therapy, and felt comfortable giving consent for assistant psychologists (with limited experience) to conduct therapy sessions using the new behavioural activation intervention. Therefore, this perception from the managerial staff was a strong facilitator in implementing the new behavioural activation programme.

'[.. ]clients have come off the CBT waiting list, which is brilliant as I manage the [ ... ] list and I usually will be looking at giving those young people CBT wait-list. So, it gives me more confidence, to be able to give our clients an intervention by an assistant psychologist who I know is following a manual, receiving supervision, guided through the session, and has limited training.' (Clinician 109, site B)

\section{Memory, attention and decision-making, and environmental context} and resources

The memory, attention and decision-making domain is described as the ability to remember information, focus on features of the environment and select between two or more options. The environmental context and resources domain included any characteristics of an individual's situation or environment that may enable or restrict them carrying out a particular behaviour. ${ }^{13}$ In this study, MHPs perceived characteristics of their work environment, such as shortage of time, high workload and working in the community, as a barrier to implementing the new behavioural activation intervention. This barrier identified under the environmental context and resources domain had a negative effect on the memory, attention and decision-making domain as, because of the busy and time restricted nature of the MHPs' work environment, they forgot about opportunities to implement the new intervention. This was particularly true for MHPs working at site B, as clinician 108 explained.
'[ ... I I think it isn't always at the front of people's minds and day to day working conditions get in the way. [ ... ], and I guess you forget if you aren't practicing something. I'm out in the community $[\ldots]$ and I have to be prepared [ ... ] and when I first started with the young person, I didn't have everything because they weren't in the pack [...]. It would be great if we could kind have them online. [ ... ].' (Clinician 108, site B)

Intentions, beliefs about capabilities, and environmental resources and context

The intentions domain is explained as the act of an individual making a conscious decision to perform a behaviour. ${ }^{13}$ Some participants perceived that, although environmental challenges are a real and ever-challenging barrier for those at the front line of care deciding to change their practice, discussion of these may at times overshadow another important but less socially acceptable barrier, such as lack of confidence, or even the feeling that the intervention should not take priority (linking to the beliefs about its value described above). This was insightfully described by clinician 103 , as follows:

' [ ... ] I think the delay in using the manual was deliberate. [ .. ] maybe, when you are less confident there is an avoidance and you are more likely to excuse yourself by saying "oh I'm too busy", or "I can't do it because I have this to do," erm, it's something that I've done.' (Clinician 103, site A)

\section{Knowledge}

Although a perception from a minority of participants, a further barrier faced by a new clinician when using the manual was their lack of knowledge of how to deal with risk in the session. Risk is defined as 'people who by the nature of their condition, symptoms, experiences, behaviour or lifestyle may be at risk of suicide or selfharm; violence or aggression (including homicide); abuse or neglect (including self-neglect), ${ }^{33}$ Although this barrier was perceived by just one participant, it is an important insight that should be highlighted. This barrier was perceived to have the potential to affect 
other new MHPs because in some services and job roles it was not mandatory to complete risk training, and therefore was perceived as necessary to add to existing training for the new behavioural activation intervention.

'[ ... ] I got to risk, and I haven't been trained on risk yet. Erm, and it's not in my mandatory training and risk came up in the sessions erm, [ ... ] I felt quite like something should have been done around risk in the training [ ... ]. That felt a little uneasy.' (Clinician 102, site A)

\section{Exploring theory-linked techniques to overcome identified implementation barriers}

Following the mapping process outlined in the methods section, 39 TDF-linked BCTs were initially identified from the TTT (see Table 2). These selected BCTs were evaluated against the APEASE criteria (see Table 3), to assess the feasibility of these behaviour change interventions within CAMHS. In detail, each BCT was appraised in terms of its affordability, practicality, effectiveness, acceptability, safety and equity, through discussion with the research team, using their academic and contextual service knowledge. For instance, the research team appraised that offering practitioners financial rewards (one of the 93 BCTs of the BCT taxonomy) could be potentially unaffordable and inequitable. Fourteen BCTs were then selected as both theory-linked and feasible in helping overcome MHP-identified barriers to implementing behavioural activation with young people. Practical examples for each BCT are listed in Table 2.

\section{Discussion}

This study explored influences on MHPs' self-reported practice behaviour when implementing behavioural activation interventions with young people in routine care. As a therapy with growing evidence for young people, which may be recommended in future clinical guidelines, it is vital to consider barriers and facilitators to its feasible implementation routine practice. Barriers and facilitators mapped onto 13 of the 14 domains of the TDF, a behavioural science framework used to explore theoretical influences on behaviour. ${ }^{14}$ Using the new TTT tool $^{18}$ and APPEASE criteria, ${ }^{30}$ these were linked to 14 evidence-based BCTs that could be integrated within routine training, meetings and supervision to help service leaders to implement behavioural activation successfully within a CAMHS.

MHP accounts suggested that their perceptions of their professional identity/role and their beliefs about capabilities to use behavioural activation were important influences on their practice. Generally, this links to other implementation science studies exploring new clinical pathways in hospitals, which have found that MHPs can be hesitant where there is a perceived mismatch with their professional identity/role ${ }^{34}$ and capabilities. ${ }^{35}$ More specifically, our study found that participants viewed behavioural activation as a therapy that would be most appropriate for use by less experienced and more junior therapeutic practitioners. This was both because of the perceived 'simple' theoretical nature of behavioural activation itself and the detailed manuals provided by study leaders. This links closely with the global public health agenda and the need to build capacity through engaging a wider psychological workforce in delivering mental healthcare. ${ }^{36}$

Additionally, in this study, MHPs' beliefs about the consequences of using behavioural activation (how successful it would be and unintended effects) operated as both a facilitator and barrier to implementation. This is important as health professionals' personal attitudes to new treatments and therapies have been found to play a role in how widely they are adopted in other studies of their perceptions. ${ }^{37}$ Specifically, some MHPs viewed behavioural activation as 'too simplistic' to work with their young people with depression, especially clients with other comorbid mental health problems. One previous study of adult patient perceptions of behavioural activation identified that some perceived the therapy as 'simplistic' and this could be a treatment engagement barrier. ${ }^{38}$ However, many participants in our study were somewhat surprised to find that their young clients engaged well with the approach, and more fully understood its theory compared with more 'complex' therapies, like CBT.

MHPs also perceived environmental context and resources as an important influence on their habitual use of behavioural activation with clients (e.g. forgetting or having little time to take opportunities to use the new behavioural activation approach). Psychological theory and research asserts that many clinical behaviours are controlled by automatic process, and are determined by habit and context rather than clinicians' deliberative thinking. ${ }^{39}$ Action and coping planning techniques are recommended to help practitioners 'plan to be routine', and are among the implementation strategies recommended In this study. ${ }^{40}$ However, some MHPs in the study questioned whether lack of time was a 'real barrier' for MHPs in delivering behavioural activation, suggesting other underlying barriers could be more relevant. Other studies exploring healthcare practitioner practices have also suggested that an expressed lack of time for an activity can sometimes be a proxy for other barriers, such as lack of confidence or a perception that the activity has little value. ${ }^{41}$

Above all, perceptions of barriers and facilitators were idiosyncratic, and there were several interacting themes and domains. This indicates the complex nature of implementing new therapies and services in routine practice and the importance of exploring MHP accounts. Exploring identified barriers and facilitators and linking these to theory-linked BCTs has been shown to increase the impact of healthcare professional training and education in physical health services in the UK and in low- and middle-income countries (e.g. Bull et $\mathrm{al}^{42}$ ).

\section{Strengths and limitations}

This study purposively sampled a range of MHPs to gather an indepth and wide range of perspectives and experiences. It was part of a wider feasibility study. ${ }^{20}$ This study adds to the limited research that has used the TDF to investigate barriers and facilitators to implementing psychological therapies, ${ }^{9,43}$ and, to our knowledge, is the first study to specifically investigate the implementation of a behavioural activation intervention. A strength of this study is that it demonstrated how the novel TTT can be used to systematically identify and link TDF domains to evidence-based BCTs, which can be used to overcome barriers and support facilitators of implementing a new intervention into clinical practice. BCTs were appraised for suitability in the specific service by using the APEASE criteria to help bridge the gap between BCTs that are evidence-based and clinicians' accounts of what may actually be feasible implementation strategies. ${ }^{28}$ Using tools like the TTT and APEASE criteria has been suggested to support the use of the TDF in the future, and overcome the common barriers to using the TDF experienced by researchers, such as linking identified TDF domains to BCTs and developing implementation interventions to support uptake of evidence-based practices. ${ }^{44}$ A limitation to using the TDF was the amount of time the framework requires from researchers, a constraint echoed in other implementation studies using the TDF. ${ }^{44}$ Also, there is no guidance about how to deal with complexities in a data-set; for example, a number of barriers perceived by staff involved multiple domains, whereas most BCTs target domains individually. ${ }^{37}$ Finally, the small sample size 
Table 2 Mapping Theoretical Domains Framework domains, barriers and facilitators onto behaviour change techniques, to help clinicians implement behavioural activation in routine practice

\begin{tabular}{|c|c|}
\hline $\begin{array}{c}\text { TDF domain } \\
\text { identity/role }\end{array}$ & $\begin{array}{c}\text { Reported clinician barrier } \\
\text { Identity as a specialised } \\
\text { clinician, do not feel } \\
\text { need for a behavioural } \\
\text { activation manual }\end{array}$ \\
& $\begin{array}{c}\text { Specialised clinicians } \\
\text { Beliefs about } \\
\text { capabilities }\end{array}$ \\
& $\begin{array}{l}\text { not be as good at using } \\
\text { the new intervention } \\
\text { compared with } \\
\text { previously learnt } \\
\text { methods }\end{array}$ \\
\hline
\end{tabular}

consequences

Worried about using it with children with comorbid problems, worried about children and young people finding the simple nature of behavioural activation patronising

Social influences

Intentions

Avoiding using the intervention

Memory, attention and decisionmaking

Environmental context and resources

Knowledge aware, decide to use established therapies, case-load and responsibilities occupy attention

Working in the community: busy, time pressure; limited capacity; changes in job role

Skills $\quad$ No previous therapeutic
experience, feeling like
you have to cover
everything in the
manual

No training around risk

\section{Reported clinician} facilitator more open to using a behavioural activation manual

Some clinicians trained in manualised therapy and felt at ease using the new therapy. New clinicians felt weak beliefs about capabilities, but wanted to build on this and practice using the manual

Simplicity of behavioural activation can help children who struggle to access or talk about thoughts and emotions, decreases the CBT waiting list
Theory-linked BCTs

mapped and evaluated as
Identity as new clinician, feasible

Social support (unspecified), framing/reframing credible resource

Problem-solving, instruction on how to perform

behaviour, demonstration of behaviour, behavioura practice and rehearsal, verbal persuasion about capability, self-talk

Comparative imagining of future consequences, pros and cons

Social support (unspecified and practical), social comparison aining are source of social support and learning from others.

Information about health consequences

Prompts and cues, adding objects to the environment

Examples of BCTs in context

Persuasive positive messages by a trusted source (e.g. study leads or supervisor) to convince staff that this is indeed part of their identity as forward-thinking, flexible formulation-driven clinicians

The team discussing barriers together and developing solutions that would then be discussed step by step, demonstrated in practice and rehearsed with colleagues, supervisors or study leads to increase clinician beliefs in their capabilities. Supervision would be a useful opportunity to assure clinicians of their capability, reflect on past successes and prompt positive self-talk

Clinicians could be prompted to think about reasons for and against using behavioural activation with different young people, including alternatives (e.g. the young person remaining on the waiting list for another therapy). Explore with clinicians the different consequences that may be expected, with the important idea that behavioural activation is 'simple, but not easy'

Group training or supervision sessions, with opportunity to access general social support; practical support to help implementation, social comparisons and learning from others about what works and how

Providing useful information about the potential positive consequences of the intervention; many other BCTs would help to ultimately influence clinician intentions

Prompts and cues such as email reminders, post-it notes or regular prompts in meetings to 'think behavioural activation' when formulating and treatment planning in the community

Social support (practical), adding objects to the environment, prompts and cues planning in the community printed sessions of the behavioural activation manual, activity scheduling sheets, information sheets for parents, extra worksheets in the workplace; providing online versions

Previous experience of Behavioural practice/ using a manual, using rehearsal the manual flexibly, gaining new skills

Instruction on how to perform behaviour, behavioural practice and rehearsal
As above, offering training, including instructions and practice/rehearsal to increase skill and confidence with different levels of detail

Practical, behaviourally informed education initiatives to develop knowledge of risk including different forms and types, risk factors, and practicing ways of handling risk in a therapeutic session 
Table 3 Identifying barriers and facilitators for a new manualised behavioural activation intervention using the Theoretical Domains Framework,

mapping these to behavioural change techniques and appraising the techniques with the APEASE criteria

\begin{tabular}{|c|c|c|}
\hline Target behaviour & TDF domain & Reported barrier \\
\hline \multirow{3}{*}{$\begin{array}{l}\text { Implementation of the } \\
\text { new manualised } \\
\text { behavioural } \\
\text { activation } \\
\text { intervention }\end{array}$} & $\begin{array}{l}\text { Professional } \\
\quad \text { identity/role }\end{array}$ & $\begin{array}{l}\text { People who viewed themselves } \\
\text { specialised clinicians. }\end{array}$ \\
\hline & $\begin{array}{l}\text { Beliefs about } \\
\text { capabilities }\end{array}$ & $\begin{array}{l}\text { Specialised clinicians worried tha } \\
\text { they would not be as good a } \\
\text { using the new intervention } \\
\text { compared with previously } \\
\text { learnt methods }\end{array}$ \\
\hline & $\begin{array}{l}\text { Beliefs about } \\
\text { consequences }\end{array}$ & $\begin{array}{l}\text { Worried about using it with } \\
\text { children with comorbid } \\
\text { problems, worried about } \\
\text { children and young people } \\
\text { finding the simple nature of } \\
\text { behavioural activation } \\
\text { patronising }\end{array}$ \\
\hline
\end{tabular}

Social influences

Reported facilitator $\quad$ BCT

APEASE

People who viewed themselves Social support (non- Yes as new clinicians specific)

Social comparison No

Social pressure Yes

credible resource Yes

Some clinicians trained in Goal-setting No

manualised therapy and felt Problem-solving Yes

at ease using the new one. Biofeedback No

New clinicians felt weak Instruction on how to Yes

beliefs about capabilities perform

but wanted to build on this Demonstration of Yes

and practice using the

manual

$$
\text { behaviour }
$$

Behavioural practice Yes

and rehearsal

Graded tasks

No

Verbal persuasion about capabilities

Focus on past

success

Self-talk

Simplicity of behavioural activation can help children who struggle to access or talk about thoughts and emotions, decreases the CBT waiting list

Information about Yes

consequences

Salience of

consequences

Information and

social and

environmental

consequences

Anticipated regret

Pros and cons

Comparative

imagining of

future

consequences

Comparative

imagining of

future

consequences

Reward

reria check

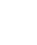

Yes

Nes

es
Yes (unspecified)

roup supervision and group training a source of social support and learning from others.

$\begin{array}{lc}\text { Intentions } & \text { Avoiding using the intervention } \\ & \\ & \\ \text { Memory, } & \text { Professionals forget to use it or are } \\ \text { attention and } & \text { not aware of it, decide to use } \\ \text { decision- } & \text { established therapies, case- } \\ \text { making } & \text { load and responsibilities } \\ & \text { occupy attention } \\ \text { Environmental } & \text { Working in the community, busy, } \\ \text { context and } & \text { time pressure, limited } \\ \text { resources } & \text { capacity, changes in job role }\end{array}$

Social support (practical)

Social rewar

Goal-setting

Information about

health

consequences

Incentive

Conserving mental resources

Prompts and cues Yes

Social support Yes (practical)

Prompts and cues Yes

Remove adverse No

stimuli

Restructuring environment

Avoidance/reducing No

exposure to cues

for behaviour

Adding objects to the Yes environment 
Table 3 (Continued)

Target behaviour

\section{TDF domain \\ Skills}

\section{Reported barrier}

No previous therapeutic experience, feeling like you have to cover everything in the manual

No training around risk

\section{Reported facilitator}

Previous experience of using a manual, using the manual flexibly, gaining new skills
BCT

\section{Graded tasks}

Behavioural

practice/

rehearsal

Instruction on how to Yes perform

Instruction on how to Yes perform

behaviour

Behavioural practice Yes and rehearsal

Information about antecedents

Biofeedback

Information about environmental and social consequences

Information about health consequences

No

Yes

No

No

No

No

APEASE criteria check Yes TDF, Theoretical Domains Framework; BCT, behaviour change technique; APEASE, affordability, practicality, effectiveness, acceptability, side-effects, equity; CBT, cognitive-behavioural therapy.

of NHS staff studied and their variation in experience of using behavioural activation limits the generalisability of the findings.

In conclusion, this qualitative study applied the TDF and other novel behavioural science methods to understand perceived barriers and facilitators to implementing behavioural activation for young people, and mapped these to evidence-based and feasible BCTs. These could be applied in future implementation of behavioural activation interventions to overcome the barriers and facilitators and support uptake within widespread clinical practice. Ultimately, this may help to improve access to psychological therapies for children and young people with depression, and enhance the uptake of research into practice.

\footnotetext{
Kate Whittenbury $(\mathbb{D}$, Faculty of Health and Education, Manchester Metropolitan University, UK; Leopold Kroll, Young People's Mental Health Research Unit, Pennine Care NHS Foundation Trust Headquarters, UK; Bernadka Dubicka, Young People's Mental Health Research Unit, Pennine Care NHS Foundation Trust Headquarters, UK; and Faculty of Biology, Medicine and Health, University of Manchester, UK; Eleanor R. Bull, Faculty of Biology, Medicine and Health, University of Manchester, UK; Eleanor
Faculty of Health and Education, Manchester Metropolitan University, UK; and Department of Anaesthesia, Manchester University NHS Foundation Trust, UK

Correspondence: Kate Whittenbury. Email: k.whittenbury@mmu.ac.uk

First received 31 Jul 2021, final revision 12 Dec 2021, accepted 7 Jan 2022
}

\section{Supplementary material}

Supplementary material is available online at https://doi.org/10.1192/bjo.2022.7.

\section{Data availability}

The data that support the findings of this study are available from the corresponding author, $\mathrm{K}$. W., upon reasonable request.

\section{Acknowledgements}

We sincerely thank the clinicians who agreed to be interviewed for this study and the other members of the wider study team, particularly Dr Jasmine Hearn, Zarah Eve and Sabah Banares.

\section{Author contributions}

K.W., E.B., L.K. and B.D. conceptualised and designed the study. K.W. conducted all analysis and worked with E.B. and L.K. to interpret data, using behavioural science tools such as the Theoretical Domains Framework and Theory and Techniques Tool. All authors drafted and revised the paper, and gave final approval for the version to be published.

\section{Funding}

This research received no specific grant from any funding agency, commercial or not-for-profit sectors.

\section{Declaration of interest}

B.D. receives funding from the National Institute of Heath Research's Health Technology Assessment Programme. This funding was unrelated to the present study.

\section{References}

1 Salari N, Hosseinian-Far A, Jalali R, Vaisi-Raygani A, Rasoulpoor S, Mohammadi $M$, et al. Prevalence of stress, anxiety, depression among the general population during the COVID-19 pandemic: a systematic review and meta-analysis. Global Health 2020; 16: 57.

2 Children's Commissioner. The State of Children's Mental Health Services 2018/ 19. Children's Commissioner, 2020 (www.childrenscommissioner.gov.uk/publication/the-state-of-childrens-mental-health-services).

3 National Institute for Health and Care Excellence (NICE). Depression in Children and Young People: Identification and Management. NICE Guideline [NG134]. NICE, 2019 (https://www.nice.org.uk/guidance/ng134).

4 Stein AT, Shumake J, Beevers C, Smits J. Therapist guided activity practice for depressive symptoms in university students: a randomized controlled trial. Cogn Ther Res 2020; 44: 499-510.

5 Tindall L, Mikocka-Walus A, McMillan D, Wright B, Hewitt C, Gascoyne S. Is behavioural activation effective in the treatment of depression in young people? A systematic review and meta-analysis. Psychol Psychother 2017; 90: 770-96.

6 Richards DA, Ekers D, McMillan D, Taylor RS, Byford S, Warren FC, et al. Cost and outcome of behavioural activation versus cognitive behavioural therapy for depression (COBRA): a randomised, controlled, non-inferiority trial. Lancet 2016; 388: 871-80.

7 Jacob M, Keeley ML, Ritschel L, Craighead WE. Behavioural activation for the treatment of low-income, African American adolescents with major depressive disorder: a case series. Clin Psychol Psychother 2013; 20: 87-96.

8 Beck A. Some simple Steps to Using Principles from Behavioural Activation to Improve the Mood of Children and Families Who Are at Home and Self-Isolating. The Association for Child and Adolescent Mental Health, 2020 (https://www. acamh.org/blog/using-behavioural-activation-to-improve-families-mentalhealth-in-lockdown/).

9 Michie S, Pilling S, Garety P, Whitty P, Eccles MP, Johnston M, et al. Difficulties implementing a mental health guideline: an exploratory investigation using psychological theory. Implement Sci 2007; 2: 8. 
10 Kazdin AE. Closing the research-practice gap: how, why, and whether. Clin Psychol Sci Pract 2016; 23: 201-6.

$11 \mathrm{Grol} \mathrm{R}$. Successes and failures in the implementation of evidence-based guidelines for clinical practice. Med Care 2001; 39: ॥46-54.

12 Eccles M, Grimshaw J, Walker A, Johnston M, Pitts N. Changing the behavior of healthcare professionals: the use of theory in promoting the uptake of research findings. J Clin Epidemiol 2005; 58: 107-12.

13 Cane J, O'Connor D, Michie S. Validation of the theoretical domains framework for use in behaviour change and implementation research. Implement Sci 2012; 7: 37.

14 Francis JJ, Stockton C, Eccles MP, Johnston M, Cuthbertson BH, Grimshaw JM, et al. Evidence-based selection of theories for designing behaviour change interventions: using methods based on theoretical construct domains to understand clinicians' blood transfusion behaviour. Br J Health Psychol 2009; 14: $625-46$

15 National Institute for Health and Care Excellence (NICE). Behaviour Change: Individual Approaches. Public Health Guideline [PH49]. NICE, 2014 (https:// www.nice.org.uk/guidance/ph49).

16 Michie S, Carey RN, Johnston M, Rothman AJ, de Bruin M, Kelly MP, et al. From theory-inspired to theory-based interventions: a protocol for developing and testing a methodology for linking behaviour change techniques to theoretical mechanisms of action. Ann Behav Med 2018; 52: 501-12.

17 Taylor JA, Phillips R, Cook E, Georgiou L, Stallard P, Sayal K. A qualitative process evaluation of classroom-based cognitive behaviour therapy to reduce adolescent depression. Int J Environ Res Public Health 2014; 11: 5951-69.

18 Human Behaviour Change Project. The Theory and Techniques Tool. Human Behaviour Change Project, 2018 (https://theoryandtechniquetool.humanbehaviourchange.org/tool).

19 Tong A, Sainsbury $\mathrm{P}$, Craig J. Consolidated criteria for reporting qualitative research (COREQ): a 32-item checklist for interviews and focus groups. Int J Qual Health Care 2007; 19: 349-57.

20 Dubicka B, Marwedel S, Banares S, Mcculloch A, Tahoun T, Hearn J, et al. Feasibility study of a new behavioural activation programme for young people with depressed mood. Child Adolesc Ment Health [Epub ahead of print] 24 May 2021. Available from: https://doi.org/10.1111/camh.12474

21 Shenton N, Redmond T, Kroll L, Parry S. Exploring behavioural activation as a treatment for low mood within CAMHS: an IPA study of adolescent experiences. Clin Child Psychol Psychiatry 2021; 26(4): 1153-69.

22 Leech BL. Asking questions: techniques for semistructured interviews. Polit Sci Polit 2002; 35: 665-8.

23 Hayfield N, Clarke V. "I'd be just as happy with a cup of tea": women's accounts of sex and affection in long-term heterosexual relationships. Womens Stud Int Forum 2012; 35: 67-74.

24 Braun V, Clarke V. Using thematic analysis in psychology. Qual Res Psychol 2006; 3: 77-101.

25 Howitt D. Introduction to Qualitative Research Methods in Psychology: Putting Theory into Practice (4th edn). Pearson, 2019.

26 Atkins L, Francis J, Islam R, O'Connor D, Patey A, Ivers N, et al. A guide to using the Theoretical Domains Framework of behaviour change to investigate implementation problems. Implement Sci 2017; 12: 77

27 Alexander KE, Brijnath B, Mazza D. Barriers and enablers to delivery of the Healthy Kids Check: an analysis informed by the Theoretical Domains Framework and COM-B model. Implement Sci 2014; 9: 60.

28 Carey RN, Connell LE, Johnston M, Rothman AJ, de Bruin M, Kelly MP, et al. Behavior change techniques and their mechanisms of action: a synthesis of links described in published intervention literature. Ann Behav Med; 53: 693707

29 Connell L, Carey R, de Bruin M, Rothman A, Johnston M, Kelly M, et al. Links between behavior change techniques and mechanisms of action: an expert consensus study. Ann Behav Med 2019; 53(8): 708-20.

30 Michie PS, Atkins DL, West PR. The Behaviour Change Wheel: A Guide to Designing Interventions. Silverback Publishing, 2014.

31 Curtis K, Van C, Lam M, Asha S, Unsworth A, Clements A, et al. Implementation evaluation and refinement of an intervention to improve blunt chest injury management-a mixed-methods study. J Clin Nurs 2017; 26: 4506-18.

32 Michie S, Johnston M, Abraham C, Lawton R, Parker D, Walker A, et al. Making psychological theory useful for implementing evidence based practice: a consensus approach. Oual Saf Health Care 2005; 14: 26-33.

33 Webster LAD, Ekers D, Chew-Graham CA. Feasibility of training practice nurses to deliver a psychosocial intervention within a collaborative care framework for people with depression and long-term conditions. BMC Nurs 2016; 15: 71

34 Rankin NM, Butow PN, Thein T, Robinson T, Shaw JM, Price MA, et al. Everybody wants it done but nobody wants to do it: an exploration of the barrier and enablers of critical components towards creating a clinical pathway for anxiety and depression in cancer. BMC Health Serv Res 2015; 15: 28.

35 Geerligs L, Rankin NM, Shepherd HL, Butow P. Hospital-based interventions: a systematic review of staff-reported barriers and facilitators to implementation processes. Implement Sci 2018; 13: 36

36 McInnis MG, Merajver SD. Global mental health: global strengths and strategies task-shifting in a shifting health economy. Asian J Psychiatry 2011; 4: 165-71.

37 McLellan JM, O'Carroll RE, Cheyne H, Dombrowski SU. Investigating midwives' barriers and facilitators to multiple health promotion practice behaviours: a qualitative study using the Theoretical Domains Framework. Implement SCi 2019; 14: 64.

38 Makarov DV, Sedlander E, Braithwaite RS, Sherman SE, Zeliadt S, Gross CP, et al. A qualitative study to understand guideline-discordant use of imaging to stage incident prostate cancer. Implement Sci 2016; 11: 118.

39 Nilsen P, Roback K, Broström A, Ellström P-E. Creatures of habit: accounting for the role of habit in implementation research on clinical behaviour change. Implement Sci 2012; 7: 53 .

40 Potthoff S, Presseau J, Sniehotta FF, Johnston M, Elovainio M, Avery L. Planning to be routine: habit as a mediator of the planning-behaviour relationship in healthcare professionals. Implement Sci 2017; 12: 24

41 Salmon P, Peters S, Rogers A, Gask L, Clifford R, Iredale W, et al. Peering through the barriers in GPs' explanations for declining to participate in research: the role of professional autonomy and the economy of time. Fam Pract 2007; 24: 269-75.

42 Bull ER, Mason C, Junior FD, Santos LV, Scott A, Ademokun D, et al. Developing nurse medication safety training in a health partnership in Mozambique using behavioural science. Global Health 2017; 13: 45.

43 Finning K, Richards DA, Moore L, Ekers D, McMillan D, Farrand PA, et al. Cost and outcome of behavioural activation versus cognitive behavioural therapy for depression (COBRA): a qualitative process evaluation. BMJ Open Lond 2017; 7: e014161.

44 Kwasnicka D, Dombrowski SU, White M, Sniehotta F. Theoretical explanations for maintenance of behaviour change: a systematic review of behaviour theories. Health Psychol Rev 2016; 10: 277-96.

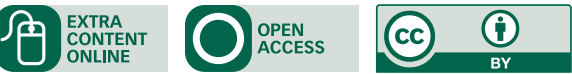

